\title{
Degradabilidade in situ da matéria seca e fração fibrosa do estilosantes Campo Grande
}

[In situ dry matter and fiber fraction degradability of the Campo Grande stylos]

\author{
R.T. Magalhães ${ }^{1}$, D.S. Corrêa ${ }^{2 *}$ \\ 1PUC Goiás- Goiânia, GO \\ ${ }^{2}$ Aluno de pós-graduação - PUC Goiás - Goiânia, GO
}

\begin{abstract}
RESUMO
Avaliou-se, pela técnica in situ, a degradabilidade da matéria seca e da fração fibrosa da leguminosa estilosantes Campo Grande (Stylosanthes spp.). A cultivar Campo Grande é composta por uma mistura física de sementes das variedades $S$. capitata e $S$. macrocephala. Para o ensaio da degradabilidade, usouse o método dos sacos de náilon, com duas incubações em um bovino adulto canulado no rúmen. $\mathrm{O}$ experimento foi realizado segundo o delineamento de blocos ao acaso, e os dados submetidos à análise de variância. A máxima degradabilidade efetiva foi atingida na taxa de passagem de $2 \%$. Para a taxa de passagem de $5 \%$, a degradabilidade efetiva foi de $68,4 \%$ para a matéria seca, $51,9 \%$ para a fibra em detergente neutro e $58,9 \%$ para a fibra em detergente ácido. Os resultados mostram que a cultivar analisada possui digestibilidade compatível com outras leguminosas tropicais atualmente utilizadas pelos produtores rurais, apresentando como vantagem o fato de ser nativa do bioma cerrado.
\end{abstract}

Palavras-chave: bovino, leguminosa tropical, degradabilidade ruminal

\begin{abstract}
Using the in situ technique, this work evaluated the dry matter and fiber fraction degradability of the Campo Grande Stylos (Stylozanthes spp.). The Campo Grande cultivar consists of a physical seed mixture of the S. capitata and S. macrocephala varieties. For the degradability assay the nylon bag method was used, with two incubations in rumen cannulated adult bovine female. In each incubation 25 samples of $7.0 \mathrm{~g}$ each were used. The samples were collected at 0, 6, 9, 12, 24, 36, 48, 72 and 96 hours. The experiment was conducted according to a randomized block design and data were submitted to variance analysis. The maximum effective degradability was in the $2 \%$ passage rate. For the $5 \%$ passage rate the Campo Grande stylos showed effective degradation of $68.4 \%$ for dry matter, $51.9 \%$ for neutral detergent fiber and 58.9\% for acid detergent fiber. The results show that the analyzed cultivar has compatible digestibility in comparison to other tropical legumes currently used by farmers, and also has the advantage of being native from the Cerrado biome, and, therefore adapted to the region's ecological conditions.
\end{abstract}

Keywords: cattle, tropical legume, degradability

\section{INTRODUÇÃO}

A avaliação nutritiva dos alimentos é de fundamental importância para a precisão e a eficiência do manejo alimentar. Enquanto a análise química é o ponto de partida na determinação do valor nutritivo dos alimentos, a utilização destes nutrientes depende do uso que o

Recebido em 1 de março de 2011

Aceito em 13 de abril de 2012

*Autor para correspondência (corresponding author)

E-mail: daniel.staciarini@terra.com.br organismo seja capaz de fazer deles (Andriguetto et al., 2002).

No Brasil é grande a disponibilidade de forrageiras leguminosas para serem utilizadas em consórcio ou como bancos de proteína. Leucaena leucocephala e Neonotonia wightii são plantas que exigem solos de maior fertilidade e são indicadas para sistemas mais intensivos de 
produção; Arachis pintoi, cultivares Amarillo e Belmonte, e Pueraria phaseoloides exigem média fertilidade; já Calopogonium mucunoides, Cajanus cajan cv. Super N, Stylosanthes guianensis cv. Mineirão, Stylosanthes macrocephala cv. Pioneiro, Stylosanthes spp. (S. capitata + S. macrocephala) cv. Campo Grande adaptam-se a solos de baixa fertilidade e podem ser usadas pela maioria dos pecuaristas (Barcellos et al., 2008). Shelton et al. (2005) ressaltaram que as leguminosas são um recurso importante, porém pouco explorado pelos produtores rurais, e que a alternativa ao seu uso será a aplicação cada vez maior e mais onerosa de fertilizantes nitrogenados e concentrados proteicos.

As leguminosas, consorciadas às pastagens tropicais, contribuem para a manutenção do aporte adequado de proteína da dieta animal, seja pela ingestão direta ou pelo efeito indireto do acréscimo de nitrogênio à gramínea (Almeida et al., 2003). Sendo assim, elas contribuem para a melhora da dieta e para a redução da quantidade de adubos químicos necessários para a manutenção da produtividade da pastagem, adicionando nitrogênio e matéria orgânica ao sistema.

O gênero Stylosanthes, pertencente à família Fabaceae, é originário das Américas Central e do Sul; a maioria das espécies é perene e possui potente sistema radicular e grande capacidade de colonização. A maior parte do estilosantes é adaptada aos solos ácidos e de baixa fertilidade natural, característicos do bioma cerrado, porém responde bem à adubação e é bem aceita pelos animais. São plantas tolerantes à toxicidade do manganês e a altas saturações de alumínio e, geralmente, pouco exigentes em fósforo (Barros et al., 2005; Grof et al., 2005; Silveira et al., 2005).

O estilosantes Campo Grande (ECG) foi lançado em 2000. Trata-se de uma leguminosa composta de uma mistura física de sementes de duas variedades de estilosantes, o $S$. capitata, $80 \% \mathrm{em}$ peso, e o S. macrocephala, $20 \%$ em peso (Verzignassi e Fernandes, 2002); as sementes são produzidas separadamente e misturadas nos pontos de venda (Fernandes et al., 2005). As plantas de $S$. capitata são subarbustos perenes, de crescimento ereto a prostrado, ramosos, com o caule coberto por pelos claros e curtos. O $S$. macrocephala é uma planta subarbustiva ou herbácea perene, de crescimento semiprostrado, galhos pilosos e cujo tamanho varia de 20 a $80 \mathrm{~cm}$ de altura (Karia et al., 2010; Silva et al., 2010). A cultivar Campo Grande é de porte herbáceo, crescimento ereto, e suas principais características são adaptação a solos arenosos, boa persistência sob pastejo, alta ressemeadura natural e tolerância à antracnose (Embrapa, 2007; Barcellos et al. 2008).

Este trabalho foi realizado com o objetivo de avaliar, pela técnica in situ, a degradabilidade ruminal da matéria seca e da fração fibrosa do Stylosanthes spp. cv. Campo Grande.

\section{MATERIAL E MÉTODOS}

Todas as etapas do trabalho foram realizadas nas áreas do Departamento de Zootecnia (Campus II) da Pontifícia Universidade Católica de Goiás. Foram utilizados, aproximadamente, $5000 \mathrm{~m}^{2}$ para o plantio e o manejo da leguminosa. Parte do material foi coletado e analisado em Laboratório de Bromatologia, e o restante foi utilizado para o ensaio de degradabilidade in situ.

As amostras de estilosantes Campo Grande foram colhidas 120 dias após a germinação, utilizando-se um quadrado de $0,5 \times 1,0 \mathrm{~m}$ em diferentes partes das parcelas e pré-secadas em estufa a $65^{\circ} \mathrm{C}$ por 72 horas ou até atingirem peso constante, moídas em moinho estacionário tipo Thomas-Willey com peneira de crivo $1 \mathrm{~mm}$ e armazenadas em potes de plástico para futuras análises bromatológicas. Outra parte do material foi moída em peneira de $5 \mathrm{~mm}$ para a realização da análise da degradabilidade in situ.

As análises bromatológicas da forrageira foram feitas pela secagem do material em estufa de ventilação forçada a $65^{\circ} \mathrm{C}$ seguida em estufa a $105^{\circ} \mathrm{C}$, determinando-se, por diferença de peso, o teor de matéria seca. A proteína bruta (PB) foi determinada pelo método de Kjeldhal (Association..., 1975). A fibra insolúvel em detergente neutro (FDN) e a fibra insolúvel em detergente ácido (FDA) calculadas pelo método sequencial (Robertson e Van Soest, 1981).

O experimento foi realizado segundo o delineamento experimental de blocos ao acaso. Os dados obtidos foram submetidos à análise de variância, e, para comparação de médias, usou-se 
o teste de agrupamento de Scott-Knott a 5\% de probabilidade.

Determinou-se a degradabilidade com duas inoculações, utilizando-se, em cada uma, uma fêmea bovina adulta (Zebu x Holandês) canulada no rúmen e alojada no tie stall, com acesso à água e à mistura mineral e alimentada com silagem de milho ad libitum. Em ambas as incubações, as amostras foram colocadas todas simultaneamente e retiradas nos tempos zero (T0), seis (T1), nove (T2), 12 (T3), 24 (T4), 36 (T5), 48 (T6), 72 (T7) e 96 (T8) horas.

As amostras foram acondicionadas em sacos de náilon com poros de $50 \mu \mathrm{m}$ de diâmetro, com dimensões de $5 \times 14 \mathrm{~cm}$, selados nas bordas e devidamente identificados. Foram utilizadas 25 amostras, 7,0g cada, em cada incubação. Para obtenção do peso dos sacos vazios, estes foram colocados em estufa a $65^{\circ} \mathrm{C}$ até atingirem peso constante, por aproximadamente 72 horas e, após 30 minutos dentro do dessecador, seus pesos foram registrados. As amostras retiradas do animal e lavadas em água corrente até que a água ficasse límpida foram secas em estufa a $55^{\circ} \mathrm{C}$ até atingirem peso constante. A seguir, determinouse a digestibilidade da MS, da FDN e da FDA.

As equações de degradabilidade foram determinadas a partir do modelo proposto por Orskov e McDonald (1979), com as adaptações propostas por Sampaio (1988):

$\mathbf{D g}=\mathbf{A}-\mathbf{B}^{*} \boldsymbol{e}^{\text {ct }}(1)$, em que: "A" é a porcentagem máxima de degradação do material contido em saquinho de náilon; "B" é um parâmetro sem valor biológico de interesse - se não houvesse tempo de colonização, ele corresponderia ao total a ser degradado pela ação dos microrganismos; "c" é a taxa fracional constante de degradação da fração que permanece no saco de náilon; “t” é o tempo de incubação no rúmen.

Após a determinação dos parâmetros A, B e c do modelo anterior, foi estimado o tempo de colonização conforme Orskov e McDonald (1979):

TC $=-1 / c^{*} \boldsymbol{e}(\mathrm{A}-\mathrm{S}) / \mathrm{B}$, em que:

A, B e c são os mesmos parâmetros definidos pela primeira equação e $S$ é a fração solúvel determinada pela porcentagem de desaparecimento no t0 de incubação, sendo obtida pela simples imersão das amostras em água. Dessa forma, a parte da equação A-S equivale ao B da equação de Orskov e McDonald (1979).

As degradabilidades efetivas (DEs) foram calculadas segundo modelo proposto por Orskov e McDonald (1979):

$\mathbf{D E}=\mathbf{S}+(\mathbf{B} * \mathbf{c}) /(\mathbf{c}+\mathbf{K})$, em que: "K" é a taxa fracional de passagem de pequenas partículas obtida após o uso de diferentes níveis de alimentação e dietas.

Os tempos de colonização (lag time) foram calculados seguindo o modelo de McDonald (1981): $(\boldsymbol{e}$ RDP t0 $-\boldsymbol{e R D P}$ t)/c, em que: $\boldsymbol{e}$ RDP t0 é o logaritmo natural do resíduo potencialmente degradável no tempo zero, $\boldsymbol{e}$ RDP t é o logaritmo natural do resíduo potencialmente degradável no último tempo de incubação e c é a taxa de degradação da fração B.

Na Tab. 1 é mostrada a composição químicobromatológica do estilosantes Campo Grande colhido aos 120 dias após germinação.

Tabela 1. Teores médios de matéria seca, matéria orgânica, proteína bruta, fibra em detergente neutro, fibra em detergente ácido, determinados pelo método sequencial, e cinzas da forrageira utilizada na incubação ruminal

\begin{tabular}{lc}
\hline Item & Estilosantes Campo Grande \\
\hline Matéria seca (\%) & 20,53 \\
Matéria orgânica & 91,92 \\
Proteína bruta (\% da MS) & 19,92 \\
Fibra em detergente neutro (\% da MS) & 51,88 \\
Fibra em detergente ácido (\% da MS) & 40,24 \\
Cinzas (\% da MS) & 8,08 \\
\hline
\end{tabular}




\section{RESULTADOS E DISCUSSÃO}

O estilosantes Campo Grande mostrou alto teor de proteína bruta, quando comparado a outras leguminosas. Padua et al. (2006) encontraram para macrotiloma (Macrotyloma axillare), kudzu tropical (Pueraria phaseoloides) e soja perene (Neonotonia wightii) valores de PB de 15,4; 15,2 e 16,5\%, respectivamente. Possenti e Valarini (2003), ao estudarem o $S$. guianensis, encontraram teor de $\mathrm{PB}$ de $17,9 \%$, enquanto Akinlade et al. (2008) estudaram quatro acessos de $S$. scabra e chegaram aos seguintes teores de proteína bruta: 15,$1 ; 15,1 ; 14,7$ e $15,0 \%$ para as cultivares Fitzroy, Seca, IITA-140 e IITA-441D, respectivamente.

Pires et al. (2006), ao avaliarem alfafa (Medicago sativa), aveia-preta (Avena strigosa), leucena (L. leucocephala) e guandu (Cajanus cajan), encontraram teores de 31,$9 ; 26,3 ; 32,6$ e $22,4 \%$ de $\mathrm{PB}$, respectivamente, e Valarini e Possenti (2006) chegaram aos valores de 22,1; 24,3; 16,7 e 23,7\% para Centrosema pubescens, Galactia striata, M. axillare e N. wightii.

Outro fator nutricional marcante das leguminosas é a qualidade de suas fibras. A fibra, segundo Theander e Aman (1980), é um produto caracterizado pela baixa solubilidade em solventes específicos e pela digestibilidade mais baixa que o amido. Os autores ainda relataram que, em alguns casos, como em plantas maduras, as concentrações de parede celular e fibras, particularmente a fibra insolúvel em detergente neutro, são similares. Os teores de fibra revelados pela análise bromatológica do Campo Grande são compatíveis com o de outras forrageiras.

Os teores de FDN encontrados por Padua et al. (2006) foram 50,4; 62,5 e 60,3\% para o macrotiloma, kudzu tropical e soja perene, respectivamente, enquanto Possenti e Valarini (2003) encontraram 48,6\% para o estilosantes e $54,2 \%$ para o siratro (Macroptilium atropurpureum). Para Pires et al. (2006), os valores foram de 52,3; 58,4; 75,9 e 73,6\%, respectivamente, para alfafa, aveia-preta, leucena e guandu, enquanto Valarini e Possenti (2006) determinaram valores de FDN de 53,2; 51,0; 46,3 e 46,6\% para $C$. pubescens, G. striata, $M$. axillare e $N$. wightii.

Os teores de FDA do Campo Grande foram mais elevados que os obtidos por Valarini e Possenti
(2006), 40,1; 36,2; 35,6 e 33,3\%, para $C$. pubescens, G. striata, M. axillare e N. wightii, respectivamente. Valores de FDA equivalentes aos do Campo Grande foram verificados por Padua et al. (2006) para macrotiloma, kudzu tropical e soja perene, 39,4; 39,5 e 40,6\%, respectivamente, e por Pires et al. (2006) para alfafa, 43,5\%, e aveia, 44,1\%. Pires et al. (2006) verificaram teores de FDA mais altos para leucena, $61,9 \%$, e guandu, 58,4\%. S. guianensis, segundo o estudo de Possenti e Valarini (2003), mostrou teor de FDA de 37,0\%. A diversidade de resultados para os teores de FDN e FDA revela grande heterogeneidade entre as forrageiras e mesmo para a mesma forrageira, dependendo das condições em que foi estudada.

Na Fig. 1 é mostrado o desaparecimento médio da matéria seca, da fibra em detergente neutro e da fibra em detergente ácido, de acordo com o tempo de incubação ruminal do estilosantes Campo Grande.

O desaparecimento no tempo zero ocorreu pela imersão das amostras no líquido ruminal e imediata lavagem. Nesse tempo, ocorre tanto a degradação imediata dos nutrientes quanto a lavagem deles - partículas muito pequenas que vazam pelos poros do saco de náilon.

Variações em relação ao desaparecimento da MS no tempo zero são verificadas na literatura. Pires et al. (2006), ao avaliarem alfafa, aveia, leucena e guandu, encontraram valores de desaparecimento no tempo zero que variaram de $25,0 \%$ para o guandu a $35,0 \%$ para a aveia, enquanto Carvalho et al. (2006a) encontraram $5,7 \%$ para o feno de guandu, Oliveira et al. (2003) 35,6\% para o feno de alfafa, e Hackmann et al. (2008) $34,1 \%$ e $38,7 \%$ para a alfafa em estágio jovem e avançado, respectivamente. Para cinco leguminosas tropicais, o desaparecimento da MS no tempo zero foi de $16,3 \%$ para Centrosema pubescens, 12,0\% para Galactia striata, 28,3\% para Macrotyloma axillare, 27,2\% para Neonotonia wightii e $11,4 \%$ para Stylosanthes guianensis (Valarini e Possenti, 2006). Essas diferenças são comuns não somente entre diferentes gêneros de leguminosas, mas dentro do próprio gênero Stylosanthes. Akinlade et al. (2008) estudaram quatro acessos de Stylosanthes scabra (cvs. Fitzroy e Seca e os acessos IITA-140 e IITA-441D) e verificaram desaparecimentos da MS, no tempo zero, de 19,$0 ; 17,2 ; 22,0$ e $20,4 \%$, respectivamente. 


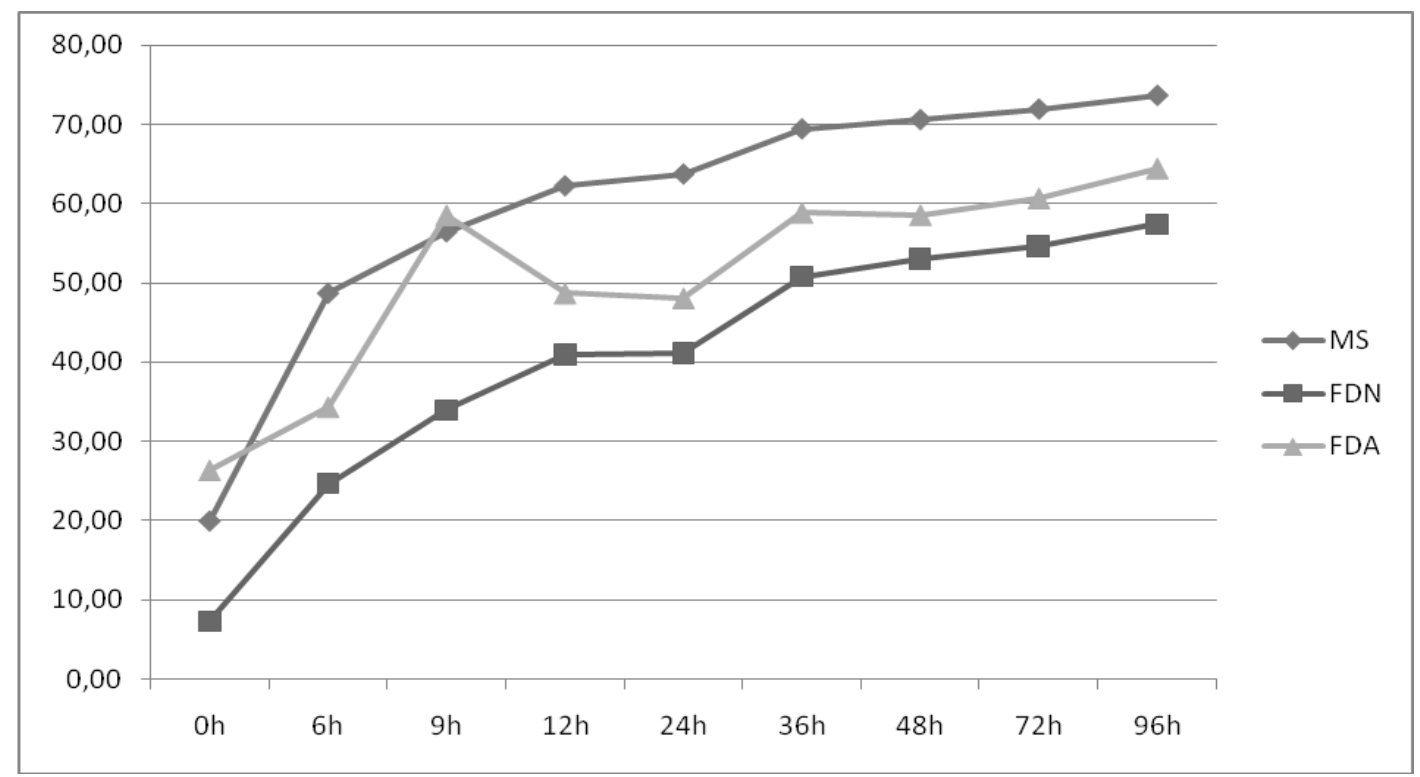

Figura 1. Desaparecimento médio (\%) da matéria seca, da fibra em detergente neutro e da fibra em detergente ácido do estilosantes Campo Grande, segundo o tempo de incubação ruminal (horas).

O desaparecimento no tempo zero ocorreu pela imersão das amostras no líquido ruminal e imediata lavagem. Nesse tempo, ocorre tanto a degradação imediata dos nutrientes quanto a lavagem deles - partículas muito pequenas que vazam pelos poros do saco de náilon.

Variações em relação ao desaparecimento da MS no tempo zero são verificadas na literatura. Pires et al. (2006), ao avaliarem alfafa, aveia, leucena e guandu, encontraram valores de desaparecimento no tempo zero que variaram de $25,0 \%$ para o guandu a $35,0 \%$ para a aveia, enquanto Carvalho et al. (2006a) encontraram $5,7 \%$ para o feno de guandu, Oliveira et al. (2003) 35,6\% para o feno de alfafa, e Hackmann et al. (2008) $34,1 \%$ e $38,7 \%$ para a alfafa em estágio jovem e avançado, respectivamente. Para cinco leguminosas tropicais, o desaparecimento da MS no tempo zero foi de $16,3 \%$ para Centrosema pubescens, 12,0\% para Galactia striata, 28,3\% para Macrotyloma axillare, 27,2\% para Neonotonia wightii e $11,4 \%$ para Stylosanthes guianensis (Valarini e Possenti, 2006). Essas diferenças são comuns não somente entre diferentes gêneros de leguminosas, mas dentro do próprio gênero Stylosanthes. Akinlade et al. (2008) estudaram quatro acessos de Stylosanthes scabra (cvs. Fitzroy e Seca e os acessos IITA-140 e IITA-441D) e verificaram desaparecimentos da MS, no tempo zero, de 19,$0 ; 17,2 ; 22,0$ e $20,4 \%$, respectivamente.
A Fig. 1 descreve uma tendência crescente de desaparecimento dos nutrientes. Verificou-se aumento da taxa de desaparecimento da FDA por volta de nove horas de incubação, o que pode ser resultado de um pico de ataque bacteriano neste tempo. O desaparecimento verificado nos tempos de $12 \mathrm{~h}$ e $24 \mathrm{~h}$, tanto para a MS quanto para a FDN e a FDA, foi muito próximo, sugerindo que, neste intervalo, a quantidade de microrganismos em contato com o alimento não se alterou.

O desaparecimento inicial da porção fibrosa foi considerado alto, ao ser comparado com outros trabalhos. Carvalho et al. (2006a), ao avaliarem Cajanus cajan, encontraram os valores de $0,09 \%$ para FDN e 0,01\% para FDA. Valores similares foram encontrados por Valarini e Possenti (2006) para FDN, 0,3; 0,2;0,1; 0,7 e $0,9 \%$ para $C$. pubescens, G. striata, M. axillare, N. wightii e $S$. guianensis, respectivamente. Magalhães et al. (2005) e Hackmann et al. (2008) observam que, por se tratar de componentes estruturais da planta, espera-se que o desaparecimento da FDN e da FDA no T0 seja próximo de zero. A alta solubilidade da fração fibrosa do alimento neste tempo de incubação pode ser explicada pela falta de homogeneidade no preparo das amostras para incubação, ou pela perda de material durante a lavagem (Magalhães et al., 2005). 
Carvalho et al. (2006b) encontraram valores elevados de desaparecimento no T0 para a FDN do Panicum maximum cv. Colonião, 15,3\%, Cynodon dactylon cv. Tifton, 11,9\%, e Brachiaria decumbens, 9,9\%.

$\mathrm{O}$ alto desaparecimento inicial influencia a degradabilidade potencial (DP) do nutriente, pois a DP é dada pela soma do desaparecimento inicial com a fração insolúvel potencialmente degradável.

As frações A e B, a degradabilidade potencial, o tempo de colonização e a degradabilidade efetiva, de acordo com a taxa de passagem, da matéria seca e da fração fibrosa do estilosantes Campo Grande são mostrados na Tab. 2. A determinação destes fatores é feita para adequar os resultados ao modelo exponencial usado para a determinação da degradabilidade efetiva (Magalhães et al., 2005). O tempo de colonização lag time indica quanto tempo os microrganismos do rúmen demoram a colonizar o alimento acondicionado no saco de náilon. Quanto menor o tempo de colonização, mais rápida se dá a degradação do alimento. Se o tempo de colonização for muito alto, a presença do alimento não degradado no rúmen impedirá o consumo de mais alimento pelo animal.

Tabela 2. Frações A e B, degradabilidade potencial (DP), tempo de colonização (TC) e degradabilidade efetiva (DE) para três taxas de passagem - 0,02; 0,05 e $0,08 / \mathrm{h}$ da matéria seca, da fibra em detergente neutro e da fibra em detergente ácido do estilosantes Campo Grande

\begin{tabular}{lccccccc} 
& $\mathrm{A}(\%)$ & $\mathrm{B}(\%)$ & $\mathrm{DP}(\%)$ & $\mathrm{TC}(\mathrm{h})$ & \multicolumn{3}{c}{$\mathrm{DE}(\%)$} \\
& & & & & $(0,02)$ & $(0,05)$ & $(0,08)$ \\
\hline $\begin{array}{l}\text { Matéria } \\
\text { seca }\end{array}$ & 19,98 & 53,63 & 73,61 & 2,39 & 71,39 & 68,39 & 65,72 \\
$\begin{array}{l}\text { Fibra em detergente } \\
\text { neutro }\end{array}$ & 7,32 & 50,09 & 57,41 & 1,91 & 55,06 & 51,93 & 49,18 \\
$\begin{array}{l}\text { Fibra em detergente } \\
\text { ácido }\end{array}$ & 26,35 & 38,13 & 64,48 & 2,50 & 62,02 & 58,89 & 56,26 \\
\hline
\end{tabular}

A fração "A" corresponde ao desaparecimento no tempo zero ou fração solúvel, "B" é a fração insolúvel potencialmente degradável. As taxas de passagem 2, 5 ou $8 \%$ /hora correspondem à baixa, média ou alta ingestão do alimento (Oliveira et al., 2003; Magalhães et al., 2005; Carvalho et al., 2006b).

Prado et al. (2004) verificaram valores de DP de $89,7 \%$ para a MS da aveia-preta e $77,1 \%$ para a MS do mombaça. As máximas degradabilidades potenciais encontradas por Hackmann et al. (2008) para o feno de alfafa foram $79,4 \%$ para a MS, $55,4 \%$ para a FDN e $53,5 \%$ para a FDA. A DP do Campo Grande obtida neste trabalho ficou próxima dos valores encontrados por Valarini e Possenti (2006), que variaram, para a MS, de $65,1 \%$ (C. pubescens) a $75,9 \%$ (M. axillare), e para a FDN, de $46,3 \%$ (C. pubescens) a $58,8 \%$ (N. wightii).

As degradabilidades efetivas da MS encontradas para o Campo Grande são ligeiramente mais altas que as encontradas por Oliveira et al. (2003) para o feno de alfafa, 70,2; 64,0 e 59,6\%, para as taxas de passagem 2, 5 e $8 \%$, respectivamente.

Segundo Carvalho et al. (2006b), a maior DP da MS encontrada foi a da braquiária, 73,0\%, e as da FDN e FDA, para o Tifton, foram, respectivamente, 71,9 e 71,1\% (Carvalho et al., 2006b). As maiores degradabilidades efetivas da MS foram obtidas com a braquiária, com 56,3; 42,6 e $35,4 \%$, para as taxas de passagem de 2,5 e $8 \%$, respectivamente; da FDN os maiores índices foram alcançados pelo colonião, com 57,$5 ; 44,7$ e $37,8 \%$ para as taxas de passagem de 2,5 e $8 \%$, respectivamente; e da FDA pelo Tifton, 52,5; 37,5 e 28,7\%, para as taxas de passagem de 2,5 e $8 \%$, respectivamente (Carvalho et al., 2006b).

Apesar da presença de substâncias que não permitem a total degradação ruminal destas plantas, como os alcaloides, taninos, saponinas e esteroides (Jerba et al., 2004), autores como Veloso et al. (2006) e Broderick (1995) ressaltaram que as leguminosas, geralmente, apresentam taxas de degradação ruminal 
superiores às das gramíneas. Jung e Allen (1995) afirmaram que, nas leguminosas, a parede celular é rica em solução de pectinas, que são solúveis em detergentes neutros.

Para a taxa de passagem 0,05 , a degradabilidade efetiva da MS de várias forrageiras variou de $23,1 \%$ para a estrela-roxa (Cynodon plectostachyrus Pliger) (Prado et al., 2004) a $71,4 \%$ para a soja perene ( $N$. wightii) (Veloso et al., 2006). Em relação à FDN, as DEs variaram de $13,1 \%$ para o guandu (C. cajan) (Carvalho et al., 2006a) a $50,9 \%$ para a aveia-preta $(A$. strigosa) (Pires et al., 2006). Para a FDA, a mínima DE encontrada foi para o guandu, 15,0\% (Carvalho et al., 2006a), e a máxima para a aveia- preta, 51,7\% (Pires et al., 2006). Para a taxa de passagem de $2 \%$, Pires et al. (2006) encontraram DEs de 80,2; 69,2 e 70,0\%, respectivamente, para a MS, a FDN e a FDA da aveia-preta.

Comparando-se com os resultados obtidos por Valarini e Possenti (2006) e Possenti e Valarini (2003), a degradabilidade da MS e da FDN do Campo Grande foi mais alta. Esses autores determinaram, à taxa de passagem de 5\%, 49,8; 52,$2 ; 64,0 ; 61,6 ; 53,5$ e 49,9\% de DE da MS e 25,$7 ; 34,3 ; 37,5 ; 36,9 ; 35,3$ e $28,3 \%$ de DE da FDN da $C$. pubescens, $G$. striata, M. axillare, $N$. wightii, $S$. guianensis e $M$. atropurpureum, respectivamente.

\section{CONCLUSÕES}

O estilosantes Campo Grande analisado revela alto valor nutritivo, resultado de sua composição químico-bromatológica e de sua alta digestibilidade. A forrageira é nativa do cerrado, portanto adaptada às condições edafoclimáticas do bioma. Tal fator, somado à sua qualidade nutricional, torna-a uma boa opção para a alimentação dos rebanhos bovinos criados na região. A alta digestibilidade da fração fibrosa revela baixos níveis de substâncias antinutricionais, como os taninos. O tempo máximo de colonização do alimento é de duas horas e meia, mostrando que as bactérias ruminais atacam rapidamente o alimento, o que, aliado à alta digestibilidade, sugere elevado consumo pelos animais. Pode-se afirmar que o Campo Grande é equivalente, tanto em termos de composição bromatológica como de digestibilidade, a outras leguminosas.

\section{REFERÊNCIAS}

AKINLADE, J.A.; FARINU, G.O.; AGBOOLA, O.O. et al. Research note: Nutritive value of four accessions of Stylosanthes scabra in the derived savanna zone of Nigeria. Trop. Grasslands, v.42, p.120-123, 2008.

ALMEIDA, R.G.; EUCLIDES, V.P.B.; NASCIMENTO JUNIOR, D. do et al. Disponibilidade, Composição Botânica e Valor Nutritivo da Forragem de Pastos Consorciados, sob Três Taxas de Lotação. Rev. Bras. Zootec., v.32, p.36-46, 2003.

ANDRIGUETTO, J.M.; PERLY, L.; MINARDI, I. et al. Nutrição Animal Volume I: as bases e os fundamentos da nutrição animal. São Paulo: Nobel, 2002. 395p.

ASSOCIATION Of Official Analytical Chemists-A.O.A.C. Official methods of analysis. 12.ed. Washington. D.C: 1094p. 1975.

BARCELLOS, A.O.; RAMOS, A.K.B.; VILELA, L. et al. Sustentabilidade da produção animal baseada em pastagens consorciadas e no emprego de leguminosas exclusivas, na forma de banco de proteína, nos trópicos brasileiros. Rev. Bras. Zootec., v.37, p.51-67, 2008.

BARROS, A.M.; FALEIRO, F.G.; KARIA, C.T. et al. Variabilidade genética e ecológica de Stylosanthes macrocephala determinadas por RAPD e SIG. Pesq. Agropec. Bras., v.40, p.899909, 2005.

BRODERICK, G.A. Desirable characteristics of forage legumes for improving protein utilization in ruminants. J. Anim. Sci., v.73, p.2760-2773, 1995.

CARVALHO, G.G.P.; PIRES, A.J.V.; VELOSO, C.M. et al. Degradabilidade ruminal do feno de alguns alimentos volumosos para ruminantes. Arq. Bras. Med. Vet. Zootec., v.58, p.575-580, 2006a.

CARVALHO, G.G.P.; PIRES, A.J.V.; VELOSO, C.M. et al. Degradabilidade ruminal do feno de forrageiras tropicais. Rev. Bras. Agroc., v.12, p.81-85, 2006b.

EMBRAPA GADO DE CORTE. Cultivo e uso do estilosantes Campo Grande. Campo Grande: Embrapa CNPGC, 2007. 11p. (Embrapa Gado de Corte, Comunicado Técnico, 105). 
FERNANDES, C.D.; GROF, B.; CHAKRABORTY, S. et al. Estilosantes Campo Grande in Brazil: a tropical forage legume success story. In: Proceedings of the $X X$ International Grassland Congress, 20., 2005, Dublin. Proceed... Dublin: Wageningen Academic Publishers, 2005. p.223.

GROF, B.; FERNANDES, C.D.; VERZIGNASSI, J.R. Recent avances in Stylosanthes research in tropical America. In: International Grassland Congress, 20., 2005, Dublin. Proceed... Dublin: Wageningen Academic Publishers, 2005. p. 232.

HACKMANN, T.J.; SAMPSON, J.D.; SPAIN, J.N. Comparing relative feed value with degradation parameters of grass and legume forages. J. Anim. Scie., v.86, p.2344-2356, 2008.

JERBA, V.F.; MEDEIROS, S.R.; FERNANDES, C.D. Forrageiras: principais fatores de antiqualidade. Campo Grande: Embrapa Gado de Corte - Documentos n.150 Embrapa Gado de Corte. 2004. 38 p.

JUNG, H.G.; ALLEN, M.S. Characteristics of plant cell walls affecting intake and digestibility of forages by ruminants. J. Anim. Scie., v.73, p.2774-2790, 1995.

KARIA, C.T.; ANDRADE, R.P.; FERNANDES, C.D. et al. Gênero Stylosanthes. In: FONSECA, D.M.; MARTUSCELLO, J.A. (Editores). Plantas Forrageiras. Viçosa:UFV, 2010. p.366 401.

MAGALHÃES， R.T.; GONÇALVES， L.C.; RODRIGUES, J.A.S. et al. Estimativa da degradabilidade ruminal de quatro genótipos de sorgo (Sorghum bicolor (L.) Moench) utilizando a técnica in situ. Acta Sci. Anim. Sci., v.27, p.483-490, 2005.

McDONALD, I. A revised model for the estimation of protein degradability in the rumen. J. Agricultural Science v. 96, n. 1, p. 251-252, 1981.

OLIVEIRA, M.V.M.; VARGAS JUNIOR, F.M.; SANCHEZ, L.M.B. et al. Degradabilidade ruminal e digestibilidade intestinal de alimentos por intermédio da técnica in situ associada à do saco de náilon móvel. Rev. Bras. Zootec., v.32, supl. 2, p.2023-2031, 2003.
ORSKOV, E.R.; McDONALD, I. The estimation of protein degradabily in the rumen from incubation measurements weighted according to rate passage. J. Agric. Sci., v.92, p.499-503, 1979.

PADUA, F.T.; ALMEIDA, J.C.C.; SILVA, T.O et al. Produção de matéria seca e composição químico-bromatológica do feno de três leguminosas forrageiras tropicais em dois sistemas de cultivo. Cienc. Rural, v.36, p.12531257, 2006.

PIRES, A.J.V.; REIS, R.A.; CARVALHO, G.G.P. et al. Degradabilidade ruminal da matéria seca, fração fibrosa e da proteína bruta de forrageiras. Pesq. Agropec. Bras., v.41, p.643-648, 2006.

POSSENTI, R.A.; VALARINI, M.J. Degradabilidade ruminal "in situ" de leguminosas forrageiras tropicais 1. In: Reunião Anual da Soc. Bras. Zootecnia, 40.,2003, Santa Maria. Anais... Santa Maria: ,SBZ, 2003. CDRom.

PRADO, I.N.; MOREIRA, F.B.; ZEOULA, L.M. et al. Degradabilidade in situ da matéria seca, proteína bruta e fibra em detergente neutro de algumas gramíneas sob pastejo contínuo. Rev. Bras. Zootec., v.33, p.1332-1339, 2004.

ROBERTSON, J.B.; Van SOEST, P.J. The detergent system of analysis and its application to humam foods. In: JAMES, W.P.T.; THEANDER, O. (Eds.). The analysis of dietary fiber in food. New York: Marcel Dekker, 1981. p.123-158.

SAMPAIO, I.B.M. Experimental designs and modeling techniques in the study of roughage degradation in rumen and growth of ruminants. 1988. 228p. Tese (PhD) University of Reading. 1988.

SHELTON, H.M.; FRANZEL, S.; PETERS, M. Adoption of tropical legume technology around the world: analysis of success. Tropical Grasslands, v.39, p.198-209, 2005.

SILVA, V.J.; DUBEUX JÚNIOR, J.C.B.; TEIXEIRA, V.I. et al. Características morfológicas e produtivas de leguminosas forrageiras tropicais submetidas a duas frequências de corte. Rev. Bras. Zootec., v.39, p.97-102, 2010. 
SILVEIRA, P.M.; BRAZ, A.J.B.P.; KLIEMANN, H.J. et al. Acumulação de Nutrientes no Limbo Foliar de Guandu e Estilosantes. Pesq. Agrop. Trop., v.35, p.133-138, 2005.

THEANDER, O.; AMAN, P. Chemical composition of some forages and various residues from feeding value determinations. $J$. Sci. Food Agric., v.31, p.31-37, 1980.

VALARINI, M.J.; POSSENTI, R.A. Research Note: Nutritive value of a range of tropical forage legumes. Trop. Grasslands. v.40, p.183187. 2006.
VELOSO, C.M.; RODRIGUEZ, N.M.; CARVALHO, G.G.P. et al. Degradabilidade ruminal da matéria seca e da proteína bruta de folhas e folíolos de forrageiras tropicais. Rev. Bras. Zootec., v.35, p.613-617, 2006.

VERZIGNASSI, J.R.; FERNANDES, C.D. Estilosantes Campo Grande: situação atual e perspectivas. Comunicado Técnico, 70, Embrapa-CNPGC, Campo Grande, 2002. 